\title{
Enhancement of HIFU Effect by Simultaneous Short Course Degarelix for Early Stage Prostate Cancer: A Pilot Study
}

\author{
Teiichiro Aoyagi*, Isao Kuroda \\ Department of Urology, Tokyo Medical University Ibaraki Medical Center, Ibaraki, Japan \\ Email: *aoyagite@tokyo-med.ac.jp
}

Received 26 February 2016; accepted 22 March 2016; published 25 March 2016

Copyright @ 2016 by authors and Scientific Research Publishing Inc.

This work is licensed under the Creative Commons Attribution International License (CC BY). http://creativecommons.org/licenses/by/4.0/

(c) (i) Open Access

\begin{abstract}
Objective: To obtain complete prostatic cell death in the treatment of early stage prostate cancer by High Intensity Focused Ultrasound (HIFU) therapy, we use Degarelix (GnRH antagonist) twice simultaneously. Patients and Methods: The first Degarelix subcutaneous injection was made two weeks before HIFU therapy, and second Degarelix was applied two weeks after the HIFU therapy. No additional maintenance Degarelix was used. To confirm the apoptosis induced by Degarelix, specimens obtained by transurethral resection simultaneously on HIFU were stained with caspase 3 and TUNEL. PSA was monitored every three months after this combination therapy as long as two years. These PSA values were compared with those who previously treated with HIFU without Degarelix. Results: Nine T1cN0M0 prostate cancer patients were enrolled to "HIFU + Degarelix" therapy. Pre treatment mean PSA level was $6.11 \pm 1.83 \mathrm{ng} / \mathrm{ml}$ (SD), and PSA 3 months after the treatment was $0.02 \pm 0.02$. These low PSA levels continued thereafter $(0.16 \mathrm{ng} / \mathrm{ml} \pm 0.19$ at 24 months). The mean pretreatment PSA level of the 34 patients underwent HIFU without Degarelix was $11.07 \pm 13.9 \mathrm{ng} / \mathrm{ml}, 3$ months post HIFU was $1.68 \pm 3.04,(2.80 \pm 3.97$ at 24 months $)$. Caspase 3 and TUNEL were positive on the glandular cells in TUR specimens of "HIFU + Degarelix" patients, suggesting Degarelix induced apoptosis. Conclusion: Although the number of our patients was small, the results of "Short course Degarelix + HIFU" would be promising for better long-term outcome than HIFU mono-therapy.
\end{abstract}

\section{Keywords}

Prostate Cancer, HIFU, Degarelix, Hormonal Therapy

\footnotetext{
${ }^{*}$ Corresponding author.
}

How to cite this paper: Aoyagi, T. and Kuroda, I. (2016) Enhancement of HIFU Effect by Simultaneous Short Course Degarelix for Early Stage Prostate Cancer: A Pilot Study. Open Journal of Urology, 6, 49-54. 


\section{Introduction}

Prostate cancer is now the most commonly diagnosed cancer in the developed countries [1]. The introduction of widespread screening using prostate specific antigen (PSA) in the decade of 1990, easy detection of prostate cancer yielded mount of early stage curable prostate cancer as well as non-clinical cancer [2]. Most of these early prostate cancers, including some non-clinical cancers, are treated with invasive methods such as total prostatectomy or high dose radiotherapy [3]. These invasive methods may have severe co-morbidities in urination and/or sexual function. So the development of less invasive modality with minor adverse effect for prostate cancer treatment has been investigated. Although, cryotherapy, radio-frequency ablation therapy and high intensity focused ultrasound therapy (HIFU) are now utilized as less invasive therapy for prostate cancer [4], these modalities have not accepted as standard therapy, presumably because the results are not as effective as surgery or radiation therapy [5], and the morbidities of these less invasive methods are not negligible [6].

More than ten thousands of early stage prostate cancer patients had undergone HIFU in the world, however HIFU does not have an appraisal as a standard therapy. The reason of this low estimation is due to lack of excellent long term results and lack of established methods to obtain stable results as well. Previous treatment results in our hospital on HIFU without Degarelix indicated, although about $60 \%$ of patients, whose post HIFU PSA level maintained below $1 \mathrm{ng} / \mathrm{mL}$, showed excellent results, among the half of the patients whose post HIFU PSA value rose again after decreased below $1 \mathrm{ng} / \mathrm{mL}$, or whose post HIFU PSA value remained three or four $\mathrm{ng} / \mathrm{mL}$, had worse prognostic results, such as cancer positive by post HIFU biopsy (unpublished data).

Prostate cancer is a hormone sensitive tumor, and even though the tumor might be high grade, hormonal therapy should be effective when the cancer is hormone naïve. Especially, more than $90 \%$ of cancer cells are said to be induced apoptosis at the first hormonal use [7]. Recent study revealed that small number of prostatic cancer cells can acquire an apoptotic tolerance by epithelial to mesenchymal transition (EMT) mechanism [8]. Moreover, some of these non-apoptotic cells will progress to castration resistant prostate cancer after obtaining ability to cell multiplication even under a hormonally castrated condition [9]. So if some other therapeutic modality such as HIFU is added at the timing when most of the cancer cells are dying by apoptosis and only small number of cells are obtaining apoptotic tolerance during the first hormonal exposure, complete cell kill may be performed. We here report our trial to add HIFU therapy at the timing when many prostatic cells are induced apoptosis by the first hormonal use for early stage prostate cancer two weeks after the initial use of Degarelix, which can properly reduce testosterone to castrate level in a few days.

\section{Methods}

Our treatment regimen is as follows, Degarelix $120 \mathrm{mg} \times 2$ subcutaneous injection, HIFU + transurethral resection of prostate (TUR-P) two weeks after the first Degarelix use under general anesthesia, Degarelix $80 \mathrm{mg}$ subcutaneous injection two weeks after HIFU, no maintenance hormonal therapy thereafter (only twice). This treatment program was evaluated by the hospital IRB (Institutional Review Board of Tokyo Medical University, Ibaraki Medical Center, approved 2013.6) and all the attended patients approved after informed consent with signature. PSA was examined every three months after the therapy. To confirm apoptosis, caspase 3 (Merck Millipore, Germany) immunohistochemical staining and TUNEL study (Promega, USA) were performed to TUR specimens obtained at HIFU treatment [10] [11]. Immunohistochemical stainings were performed to formalin fixed paraffin embedded section following instruction [12]. Anti-caspase 3 antibody (cleaved form, polyclonal rabbit anti-human) was used in $10 \times$ solution activated by microwave. Nine patients treated with HIFU + Degarelix were enrolled, and post HIFU PSA values were compared with the results of 34 patients treated with HIFU only. These 34 patients were treated at our hospital before Degarelix could be clinically available in Japan. PSA reduction rate at three months after each therapy \{(pre-PSA-post 3 months PSA)/pre-PSA $\}$ was compared between these groups and evaluated by unpaired t-test using stat view 4.5 (Abacus concepts. USA).

\section{Results}

\subsection{Profiles and Treatment Results of Degarelix + HIFU Patients}

Nine T1cN0M0 prostate cancer patients were enrolled to HIFU + Degarelix therapy. Profiles and treatment results and/or adverse events of these patients are listed in the Table 1 . The average of pre treatment PSA was $6.11 \pm 1.83 \mathrm{ng} / \mathrm{ml}(\mathrm{SD})$, and PSA 3 months after the treatment was $0.02 \pm 0.02$. These low PSA levels continued 
Table 1. Patient profiles and events after therapy.

\begin{tabular}{|c|c|c|c|c|c|c|c|}
\hline & \multirow{2}{*}{ Age } & \multirow{2}{*}{ Gleason } & Positive & PSA & (ng/ml) & TUR-P & \multirow{2}{*}{ Adverse event } \\
\hline & & & biopsy & pre. & 12 mo. & (grams) & \\
\hline 1 & 64 & $3+3$ & $1 / 12$ & 5.26 & 0.070 & $16.0^{*}$ & \\
\hline 2 & 64 & $4+3$ & $5 / 12$ & 4.25 & 0.012 & 0.4 & \\
\hline 3 & 73 & $4+3$ & $2 / 6$ & 7.64 & 0.094 & 0.4 & Urethral stricture \\
\hline 4 & 76 & $4+3$ & $1 / 12$ & 6.60 & 0.008 & 0.5 & Urethral stricture \\
\hline 5 & 66 & $4+3$ & $1 / 12$ & 5.03 & 0.008 & 2.5 & Urethral stricture \\
\hline 6 & 65 & $3+4$ & $2 / 12$ & 9.30 & 0.428 & 4.0 & PSA failure $18 \mathrm{mo}$ \\
\hline 7 & 60 & $3+4$ & $1 / 12$ & 4.70 & 0.015 & $14.0^{*}$ & \\
\hline 8 & 65 & $3+4$ & $4 / 12$ & 5.87 & 0.042 & $17.0^{*}$ & Epididymitis \\
\hline 9 & 59 & $3+4$ & $1 / 12$ & 8.61 & 0.008 & 1.2 & Mild incontinence \\
\hline
\end{tabular}

Positive biopsy shows positive biopsy cores/total biopsied cores. PSA values shows pre-treatment and 12 months post-treatment values. ${ }^{*}$ TUR-P was performed two months before HIFU to reduce prostatic volume due to benign prostatic hyperplasia, for others, TUR-P was done simultaneously at HIFU.

thereafter $(0.16 \mathrm{ng} / \mathrm{ml} \pm 0.19$ at 24 months). Marked shrinkage of prostate gland with open bladder neck was noted on MRI 3 months after HIFU therapy as indicated in the Figure 1. One patient (\#6) showed PSA failure at 18 months (nadir $+1.2 \mathrm{ng} / \mathrm{ml}$ ) and he selected additional external radiation therapy and excluded from the 24 months PSA data. This patient underwent the first HIFU therapy with neoadjuvant LHRH hormonal therapy for three months eight years ago, so this was not the first hormonal therapy for him. Three patients showed marked prostatic urethral stricture, which was treated by internal urethrotomy (\#3, \#4 patients) and urethral sounding in outpatient basis (\#5).

\subsection{Immunohistochemical Staining}

Caspase 3 and TUNEL were positive on the glandular cells in TUR specimens of "HIFU + Degarelix" patients, indicating Degarelix induced apoptosis at the time of HIFU therapy (Figure 2).

\subsection{Comparison with HIFU Mono-Therapy}

The mean pretreatment PSA level of the 34 patients underwent HIFU without Degarelix was $11.07 \pm 13.9 \mathrm{ng} / \mathrm{ml}$, 3 months post HIFU was $1.68 \pm 3.04$, and 24 months post HIFU was $2.80 \pm 3.97 \mathrm{ng} / \mathrm{mL}$. All the patients treated with "HIFU + Degarelix" showed 3 months post treatment PSA level below $0.1 \mathrm{ng} / \mathrm{ml}$. The PSA decrease rate from pre-treatment to 3 months post-treatment of HIFU + Degarelix patients was statistically larger when it was compared with HIFU only patients (Table 2).

\section{Discussion}

Although HIFU therapy has been used as non-invasive treatment for early stage prostate cancer, it is not sited as standard therapy in any guidelines in the world. Haar and Coussios [13] reported the fundamental treatment mechanism of HIFU attributes to thermal effect up to 90 degrees centigrade produced by aggregated strong ultrasound energy, and mechanical effect by acoustic pulses producing cavitations, microstreaming and radiation force. The reason why HIFU has not accepted as a standard therapy, is presumably due to the lack of reliable long term results [14]. The possible cause of this incomplete treatment might be the appearance of untreated niche produced by the minute movement of the patient and/or ballooning of prostate by heat during the treatment procedures [15]. And if this untreated niche contained cancer, the tumor will relapse in the long run. The superficial lesion close to prostate capsule has abundant blood supply and easily escape the heat, so these parts may apt to more produce untreated niche than the central part.

Bruchovsky et al. [16] reported that more than $90 \%$ of implanted hormone naïve Shionogi cancer cells went into apoptosis at the first exposure of hormonal therapy. Degarelix is a sole agent, which can certainly reduce 

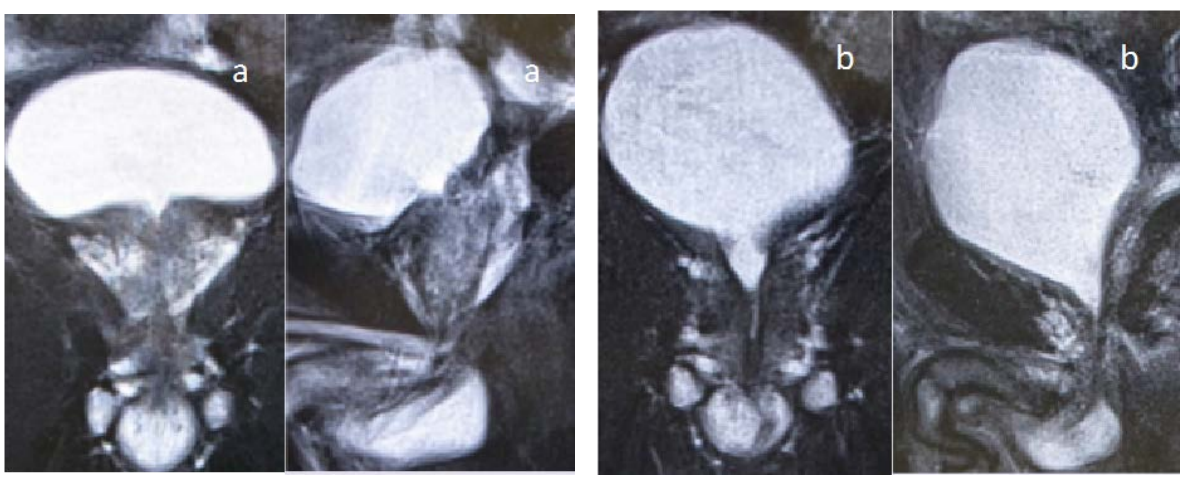

Figure 1. Representative prostatic lateral and coronal MRI findings of "Short course Degarelix + HIFU” treatment in pre (a) and post 3 months (b) treatment. Most of the prostate disappeared after 3 months.
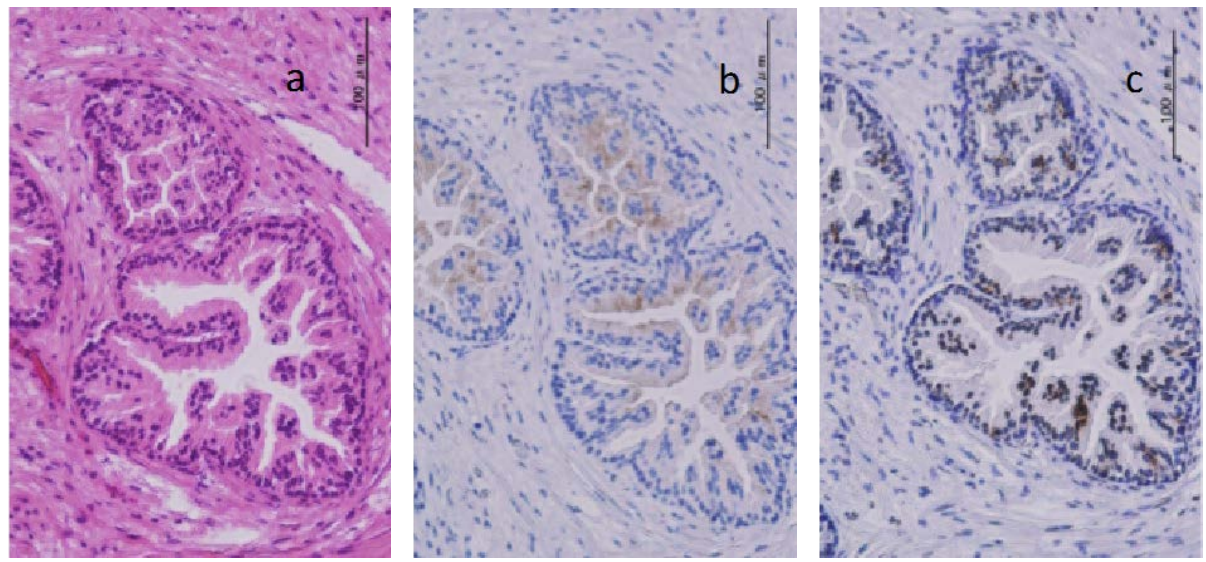

Figure 2. Apoptotic change are observed after two weeks of Degarelix use in TUR-P specimens at HIFU treatment. Adenoma cells stained with H \& E 80× (a), Caspase 3 (b) and TUNEL (c), indicating these cells are going to apoptosis.

Table 2. Comparison with mono-therapy.

\begin{tabular}{|c|c|c|c|c|c|c|c|}
\hline & \multicolumn{4}{|c|}{ PSA (mean \pm SD ng/ml) } & \multirow{2}{*}{$\begin{array}{c}\text { pre-3 } \\
\text { pre }\end{array}$} & \multirow[t]{2}{*}{ Failure } & \multirow{2}{*}{$\mathrm{n}$} \\
\hline & pre. & 3 & 6 & 24 mo. & & & \\
\hline \multirow[t]{2}{*}{ HIFU + Degarelix } & 6.11 & 0.02 & 0.02 & 0.16 & $99.6^{*}$ & 11.1 & 9 \\
\hline & \pm 1.83 & \pm 0.02 & \pm 0.02 & \pm 0.19 & $\%$ & $\%$ & \\
\hline \multirow[t]{2}{*}{ HIFU only } & 11.07 & 1.68 & 1.93 & 2.80 & $84.8^{*}$ & 23.5 & 34 \\
\hline & \pm 13.9 & \pm 3.04 & \pm 2.65 & \pm 3.97 & $\%$ & $\%$ & \\
\hline
\end{tabular}

PSA values shows pre-treatment, 3, 6 and 24 months after treatment. PSA reduction rate ${ }^{*}$ is high in HIFU + Degarelix therapy compared to HIFU mono-therapy in 3 months $(\mathrm{p}<0.05)$. The rate of treatment failure is calculated at the treatment results of 24 months by PSA value (nadir +1.2$)$ and/or post-treatment positive biopsy.

testosterone as low as castration level in a few days and induce massive apoptosis of prostatic cells [17]. We expected additional effect by simultaneous use of HIFU and Degarelix, and expected a 100\% prostatic cell kill that may not be accomplished by HIFU therapy only. Our results showed that simultaneous short course Degarelix and HIFU therapy yielded reduction of PSA values as low as those after surgical prostatectomy, and also indicated the similar MRI image as those after surgical resection (Figure 1). We presume hormonally induced apoptosis and HIFU induced heat damage affect not only glandular but also interstitial tissue worked as a multiplier effect consequently cause total organ damage.

The reason why the hormonal therapy must continue almost eternally is presumed that small numbers of prostatic cancer cells turn into stem cells by means of EMT and remain as cell arrest condition obtaining apop- 
tosis-durability after the first hormonal therapy [8] [9]. In our therapy, HIFU effectively damage these EMT inducing cells by the first use of Degarelix, and also damage the interstitial cells those are supposed to assist EMT.

Cryotherapy needs trans-perineal multiple needle punctures. Therefore HIFU is the only non-invasive therapy for early stage prostate cancer except for external beam radiation therapy. We are convinced that by more experiences, simultaneous use of short Degarelix and HIFU therapy would recognize as an alternative standard therapy of prostatectomy or radiation therapy.

\section{Conclusion}

Although the number of our patients was small, the results of "Short course Degarelix + HIFU" were promising for a better long-term outcome than HIFU mono-therapy. The simultaneous use of Degarelix and HIFU could compensate each weak point that small number of cancer cells might still survive after the single therapy, and yield the possibility to obtain total cancer cell kill that is indispensable to make "HIFU" a standard therapy.

\section{Competing Interests}

The authors declare that they have no competing interests on this subject.

\section{References}

[1] Fitzmaurice, C., Dicker, D., Pain, A., Hamavid, H., Moradi-Lakeh, M., MacIntyre, M.F., et al. (2015) The Global Burden of Cancer 2013. JAMA Oncology, 1, 505-527. http://dx.doi.org/10.1001/jamaoncol.2015.0735

[2] Schröder, F.H., Hugosson, J., Roobol, M.J., Tammela, T.L., Ciatto, S., Nelen, V., et al. (2009) Screening and Prostate-cancer Mortality in a Randomized European Study. The New England Journal of Medicine, 360, 1320-1328. http://dx.doi.org/10.1056/NEJMoa0810084

[3] Loeb, S., Bjurlin, M.A., Nicholson, J., Tammela, T.L., Penson, D.F., Carter, H.B., et al. (2014) Overdiagnosis and Overtreatment of Prostate Cancer. European Urology, 65, 1046-1055. http://dx.doi.org/10.1016/j.eururo.2013.12.062

[4] Eggener, S. (2010) Ablative Focal Therapy for Primary Treatment of Prostate Cancer. AUA Update Series, $29,22-32$.

[5] Blana, S., Brown, S.C.W., Chaussy, C., Conti, G.N., Eastham, J.A., Ganzer, R., et al. (2009) High-Intensity Focused Ultrasound for Prostate Cancer: Comparative Definitions of Biochemical Failure. BJU International, 104, 1058-1062. http://dx.doi.org/10.1111/j.1464-410X.2009.08518.x

[6] Crouzet, S., Chapelon, J.Y., Rouvière, O., Mege-Lechevallier, F., Colombel, M., Tonoli-Catez, H., et al. (2014) Whole-gland Ablation of Localized Prostate Cancer with High-Intensity Focused Ultrasound: Oncologic Outcomes and Morbidity in 1002 Patients. European Urology, 65, 907-914. http://dx.doi.org/10.1016/j.eururo.2013.04.039

[7] Akakura, K., Bruchovsky, N., Goldenberg, S.J., Rennie, P.S., Buckley, A.R. and Sullivan, L.D. (1993) Effects of Intermittent Androgen Suppression on Androgen-Dependent Tumors. Cancer, 71, 2782-2790. http://dx.doi.org/10.1002/1097-0142(19930501)71:9<2782::AID-CNCR2820710916>3.0.CO;2-Z

[8] Sun, Y., Wang, B.E., Leong, K.G., Yue, P., Li, L., Jhunjhunwala, S., et al. (2011) Androgen Deprivation Causes Epithelial-Mesenchymal Transition in the Prostate: Implication for Androgen-Deprivation Therapy. Cancer Research, 72, 527-536. http://dx.doi.org/10.1158/0008-5472.CAN-11-3004

[9] Li, P., Yang, R. and Gao, W.Q. (2014) Contribution of Epithelial Mesenchymal Transition and Cancer Stem Cells to the Development of Castration Resistance of Prostate Cancer. Molecular Cancer, 13, 55. http://dx.doi.org/10.1186/1476-4598-13-55

[10] Gavrieli, Y., Sherman, Y. and Ben-Sasson, S.A. (1992) Identification of Programmed Cell Death in Situ via Specific Labeling of Nuclear DNA Fragmentation. The Journal of Cell Biology, 119, 493-501. http://dx.doi.org/10.1083/jcb.119.3.493

[11] Nicholson, D.W. and Thornberry, A. (1997) Caspases; Killer Proteases. Trends in Biochemical Sciences, 22, $299-306$. http://dx.doi.org/10.1016/S0968-0004(97)01085-2

[12] Cuello, A.C., Ed. (1993) Immunohistochemistry II. John Wiley \& Sons, Ltd., New York.

[13] Haar, G.T. and Coussios, C. (2007) High Intensity Focused Ultrasound: Physical Principles and Devices. International Journal of Hyperthermia, 23, 89-104. http://dx.doi.org/10.1080/02656730601186138

[14] Cordeiro, E.R., Cathelineau, X., Thuroff, S., Marberger, M., Crouzet, S. and de la Rosette, J.J.M.C.H. (2012) HighIntensity Focused Ultrasound (HIFU) for Definitive Treatment of Prostate Cancer. BJU International, 110, 1228-1242. http://dx.doi.org/10.1111/j.1464-410X.2012.11262.X

[15] Shoji, S., Uchida, T., Nakamoto, M., Kim, H., Abreu, A.D.C., Leslie, S., et al. (2013) Prostate Swelling and Shift Dur- 
ing High Intensity Focused Ultrasound: Implication for Targeted Focal Therapy. The Journal of Urology, 190, 12241232. http://dx.doi.org/10.1016/j.juro.2013.03.116

[16] Bruchovsky, N., Rennie, P.S., Coldman, A.J., Goldenberg, S.L., To, M. and Lawson, D. (1990) Effects of Androgen Withdrawal on the Stem Cell Composition of the Shionogi Carcinoma. Cancer Research, 50, 2275-2282.

[17] Shore, N.D. (2013) Experience with Degarelix in the Treatment of Prostate Cancer. Therapeutic Advances in Urology, 5, 11-24. http://dx.doi.org/10.1177/1756287212461048 